Check for updates

Cite this: Mater. Adv., 2021, 2, 2408

Received 22nd October 2020 Accepted 28th February 2021

DOI: 10.1039/d0ma00823k

rsc.li/materials-advances

\section{A titanium dioxide-carbon nanotube hybrid to simultaneously achieve the mechanical enhancement of natural rubber and its stability under extreme frictional conditions $\uparrow$}

\author{
Le Wan, Cong Deng, (D) * Ze-Yong Zhao, Hai-Bo Zhao (D) and Yu-Zhong Wang
}

\begin{abstract}
Currently, carbon black as an efficient reinforcing agent dominates the reinforcement field of natural rubber (NR). However, its general loading amount is quite high for achieving the reinforcement of NR. In this work, titanium oxide-carbon nanotubes $\left(\mathrm{TiO}_{2}-\mathrm{CNTs}\right)$ were prepared by using the hydrothermal method. When a small amount of $\mathrm{TiO}_{2}-\mathrm{CNTS}$ additive was used to reinforce NR, significant mechanical enhancement was achieved. Experimental results confirmed that the tensile strength and elongation at the break of NR containing $3.0 \mathrm{wt} \% \mathrm{TiO}_{2}-\mathrm{CNTs}\left(\mathrm{NR} / 3 \mathrm{TiO}_{2}-\mathrm{CNTs}\right)$ were $32.0 \mathrm{MPa}$ and $1604 \%$, corresponding to an increase by about $79.5 \%$ and $14.5 \%$, respectively, in comparison with that of pristine NR. Moreover, thermal analysis confirmed that the initial decomposing temperature of NR was promoted to $313.5^{\circ} \mathrm{C}$ from $287.9{ }^{\circ} \mathrm{C}$ after the incorporation of only 3 wt \% $\mathrm{TiO}_{2}-\mathrm{CNTs}$, which was raised by $25.6{ }^{\circ} \mathrm{C}$. An intensive friction test confirmed that the maximum temperatures at the surfaces of $\mathrm{NR} / 3 \mathrm{TiO}_{2}-\mathrm{CNTS}_{\mathrm{s}}$ and $\mathrm{NR} / 5 \mathrm{TiO}_{2}-\mathrm{CNTs}$ were 217 and $210{ }^{\circ} \mathrm{C}$, respectively, which decreased by 29 and $36{ }^{\circ} \mathrm{C}$ in comparison with that of NR. The study of the mechanical enhancement confirmed that the uniform dispersion of $\mathrm{TiO}_{2}-\mathrm{CNTs}$ and superior interfacial interactions between $\mathrm{NR}$ and $\mathrm{TiO}_{2}-\mathrm{CNTs}$ played a dominant role in the mechanical enhancement of $\mathrm{NR} / \mathrm{TiO}_{2}-\mathrm{CNTs}$ composites. For the improved stability of $\mathrm{NR} / \mathrm{TiO}_{2}-$ CNTs composites, the physical barrier action of $\mathrm{TiO}_{2}-\mathrm{CNTs}$ to heat and oxygen, excellent heat dispersion of CNTs, and the increased graphitization degree at the surface played a vital role. The $\mathrm{TiO}_{2}-\mathrm{CNTS}$ show specific advantages in simultaneously reinforcing the mechanical properties of NR and promoting its stability under extreme friction condition.
\end{abstract}

\section{Introduction}

The working environment of aircraft tires is very harsh during landing, including high speed, high load, high temperature, and intensive friction. In this case, the temperature at the tread of the aircraft tires rises sharply and the instantaneous temperature can reach $300-400{ }^{\circ} \mathrm{C}$, which causes the tread of the aircraft tires to be damaged easily; this kind of damage is a great threat to the safety of human beings and aircrafts. In the current work, carbon black was applied to reinforce NR. As an efficient reinforcing agent, carbon black dominates the reinforcing field of NR. Moreover, it has also been confirmed that carbon blackreinforced NR possesses high thermal stability. Matheson et al. ${ }^{1}$

The Collaborative Innovation Center for Eco-Friendly and Fire-Safety Polymeric Materials, National Engineering Laboratory of Eco-Friendly Polymeric Materials (Sichuan), State Key Laboratory of Polymer Materials Engineering, Analytical \& Testing Center, Sichuan University, Chengdu 610064, China.

E-mail: dengcong@scu.edu.cn

$\dagger$ Electronic supplementary information (ESI) available. See DOI: 10.1039/ d0ma00823k studied the effect of carbon black on the thermal decomposition behavior of NR and results showed that the presence of carbon black did not apparently have any negative affect on the thermal stability of NR. Although carbon black has its own advantages in reinforcing NR, the high loading amount of carbon black is a shortcoming in the case of fulfilling the requirements of mechanical, high-temperature stability, and other properties in fabricating the tread material of aircraft tires.

In order to prepare NR composites with excellent mechanical properties and high-temperature stability, many researchers have done much work. In terms of the thermal stability of NR composites, some researchers have deeply investigated the thermal decomposition behavior of NR and further explored some novel NR-based composites. Straus et al. ${ }^{2}$ studied the thermal decomposition behavior of vulcanized rubber under vacuum condition and found that the crosslinking bond was easy to break at the pyrolysis temperature; also, the effect of crosslinking became invalid at a higher temperature. Ginger et al. ${ }^{3}$ studied the thermal decomposition behavior of crosslinked polyisoprene and found that the molecular chain rearranged and resulted in the formation 
of terminal double bond during heating. In addition, due to the crosslinking, both the thermal stability and thermal-oxidation stability were enhanced. For NR, both vulcanization and crosslinking may affect the type and yield of the thermal decomposition products. Generally, the yield of the produced monomers and dimers will decrease with increasing crosslinking density, but the yield of 3-methyl-1,3-pentylene will not remarkably fluctuate with the change in the crosslinking density. ${ }^{4-6}$ Chen et al. ${ }^{7}$ pyrolyzed cis-1,4-polyisoprene at different temperature ranges; the results showed that the concentrations of isoprene and dipentene formed at relatively low temperature were higher. At relatively high temperature, a high yield of hydrocarbon was obtained due to the intensive decomposition of the polymer. ${ }^{8-10}$

On the basis of the above fundamental research, some novel NR-based composites with improved thermal stability and mechanical properties were developed, in which nanoparticles have been proved to be very efficient to achieve the improved thermal properties. Here, nanoparticles mainly contain carbon nanotubes, modified montmorillonite (MMT), silica, calcium carbonate, carbon black, and starch. Khanlari et al. ${ }^{11}$ used modified MMT to promote the thermal stability of NR. The results confirmed that the thermal decomposition of the MMTfilled nanocomposites shifted towards the higher temperature range, and the temperatures at 20 and $50 \mathrm{wt} \%$ mass loss were increased by 20 and $15{ }^{\circ} \mathrm{C}$, respectively. Among different types of nanofillers, CNTs have also been demonstrated to be very efficient in improving the thermal stability and mechanical properties of NR. Fakhru' I-Razi et al. found that a high strain value was obtained for the nanocomposite with $1.0 \mathrm{wt} \%$ CNTs. Moreover, better heat dispersion and higher thermal stability were simultaneously achieved for the NR/CNTs nanocomposites. However, due to the fact that CNTs are easy to agglomerate and entangle, they are difficult to uniformly disperse in the matrix. ${ }^{12,13}$ In addition, it has been confirmed that $\mathrm{TiO}_{2}$ nanoparticles can improve the thermal stability and high temperature resistance of polymers. Hayeemasae et al. ${ }^{14}$ found that $\mathrm{TiO}_{2}$ nanoparticles had an apparent influence on the thermal stability of NR. The results showed that the decomposition temperatures at 10 and $50 \%$ weight loss for NR composite were remarkably raised when a small amount of $\mathrm{TiO}_{2}$ was added in the NR composite.

According to a previous report, ${ }^{15}$ compared with the monocomponent filler, the synergy of two or more kinds of reinforcing materials can improve the dispersion of fillers and meanwhile endow rubber with better specific properties or better comprehensive properties. Therefore, the joint action of CNTs and $\mathrm{TiO}_{2}$ might have a positive influence on the mechanical enhancement and thermal stability of NR. In this work, the $\mathrm{TiO}_{2}-\mathrm{CNTs}$ were prepared by the sol-gel method and used to fabricate the $\mathrm{NR} / \mathrm{TiO}_{2}-\mathrm{CNT}$ composite via the latex composite method in order to fabricate the NR composites with excellent comprehensive properties. ${ }^{16}$ The mechanical properties and stability of the NR composites were investigated with the aid of different measurements. Moreover, the corresponding mechanisms for the improved mechanical properties and stability were discussed in detail.

\section{Experimental section}

\subsection{Materials}

NR was purchased from Tianjin Changli Rubber Co., Ltd (China), whose dry rubber content (DRC) was about $60 \%$. Carbon black (CB, N330) was supplied by Cabot Corporation (USA). Carbon nanotubes (TNSMC3, hydroxylation, industrial grade) were provided by Institute of Organic Chemistry (Chinese Academy of Sciences), and their outer diameter and length are about 10-20 nm and 0.5-2.0 $\mu \mathrm{m}$, respectively. Anhydrous ethanol (analytical reagent), titanium isopropanol (analytical reagent), isopropanol (analytical reagent), and formic acid (analytical reagent) were purchased from Chengdu Kelong Chemical Reagent Factory (China). Deionized water was self-made. Sulfur (industrial grade) was obtained from Yisheng New Material Co., Ltd (China). Zinc oxide (industrial grade) was produced by Dalian Zinc Oxide Co., Ltd (China). Stearic acid (SA) was purchased from Taike Browning Co., Ltd (China). The antioxidant $N$-isopropyl- $N^{\prime}$-phenyl-4-phenylenediamin (4010NA) was purchased from Sinopec Group Nanjing Chemical Industry Co., Ltd (China). Vulcanization accelerator (CZ) was supplied by Kemai Chemical Co., Ltd (China).

\subsection{Preparation of $\mathrm{TiO}_{2}-\mathrm{CNTs}$ nanoparticles}

First, $109.2 \mathrm{~mL}$ deionized water and $10.8 \mathrm{~mL}$ isopropanol were mixed in a $250 \mathrm{~mL}$ flask. Then, CNTs were added into the mixed solution containing isopropanol. After being stirred for $2 \mathrm{~h}$, the CNT solution was obtained. Next, $13.6 \mathrm{~mL}$ titanium isopropanol was slowly added to the CNT solution through the separating funnel and the dripping time was about $30 \mathrm{~min}$. Then, the hydrolysis reaction was maintained for $2 \mathrm{~h}$ at room temperature, accompanied by stirring. Afterwards, the product was washed with absolute ethanol and deionized water, and then the washed products were put into a vacuum oven and dried at $80{ }^{\circ} \mathrm{C}$ for $5 \mathrm{~h}$. Finally, the $\mathrm{TiO}_{2}-\mathrm{CNTs}$ nanoparticles were obtained.

\subsection{Preparation of the $\mathrm{NR} / \mathrm{TiO}_{2}-\mathrm{CNTs}$ nanocomposites}

The NR/TiO ${ }_{2}-\mathrm{CNTs}_{\mathrm{N}}$ composites were prepared by adding different contents of $\mathrm{TiO}_{2}-\mathrm{CNTs}$ into the NR latex, as shown in Table 1. Firstly, $\mathrm{TiO}_{2}-\mathrm{CNTs}$ nanoparticles were added into a large beaker containing $200 \mathrm{~mL}$ deionized water. After stirring for $1 \mathrm{~h}$, followed by ultrasonic treatment for $2 \mathrm{~h}$, the latex was slowly added into the beaker and stirred for $3 \mathrm{~h}$. Here, the sonication power was $300 \mathrm{~W}$. Then, formic acid solution was slowly incorporated in the mixed solution until it was completely demulsified and settled. Then, the

Table 1 The formulation of the composites

\begin{tabular}{llllll}
\hline Materials & \multicolumn{5}{l}{ Additive contents $\left(\mathrm{phr}^{a}\right)$} \\
\hline NR & 100 & 100 & 100 & 100 & 100 \\
TiO $_{2}-$ CNT & 1 & 2 & 3 & 5 & 7 \\
Stearic acid & 1 & 1 & 1 & 1 & 1 \\
Zinc oxide & 5 & 5 & 5 & 5 & 5 \\
$4010 N A$ & 2 & 2 & 2 & 2 & 2 \\
CZ & 1.5 & 1.5 & 1.5 & 1.5 & 1.5 \\
Sulfur & 2 & 2 & 2 & 2 & 2
\end{tabular}

${ }^{a}$ The number in the front of the materials represent its content and the unit is phr. 
rubber composites were cut into small pieces and washed with deionized water and ethanol until the formic acid was completely removed. Finally, these small pieces were put into a vacuum oven and dried at $80{ }^{\circ} \mathrm{C}$ for $12 \mathrm{~h}$, and then the $\mathrm{NR} / \mathrm{TiO}_{2}-\mathrm{CNTs}$ nanocomposites were obtained. Finally, different $\mathrm{NR} / \mathrm{TiO}_{2}-\mathrm{CNTs}$ nanocomposites were mechanically blended with the vulcanizing agent, curing agent, and other additives by an open mixer. During mixing, the speed of the mill was $60 \mathrm{rpm}$ and the nip gap of the mill was $0.5 \mathrm{~mm}$. After blending, these rubber composites were vulcanized by a flat curing machine (Qingdao Yadong Rubber Machinery Co. Ltd, China) at $150{ }^{\circ} \mathrm{C}$ and then pressing was continued for $5 \mathrm{~min}$ at room temperature to maintain their shape. Here, the curing time (10 $\mathrm{min}$ ) was determined by $t_{90}$. In hydraulic heating press, the pressure was $15 \mathrm{MPa}$ and the size of the mold was $100 \mathrm{~mm} \times 100 \mathrm{~mm} \times 2 \mathrm{~mm}$. Finally, the vulcanized $\mathrm{NR} / \mathrm{TiO}_{2}-$ CNTs plates was tailored by a specific cutter according to the test standards. In addition, 50 phr carbon black enhanced NR composites, which were used for the friction test, were also prepared according to the same procedure as that mentioned above.

\subsection{Measurements}

Thermogravimetric analysis (TGA) was carried out on a thermal analyzer (NETZSCH, TG209, Germany) under nitrogen/air atmosphere and the heating rate was $10{ }^{\circ} \mathrm{C} \mathrm{min}^{-1}$. The mechanical properties of $\mathrm{NR}$ and the $\mathrm{NR} / \mathrm{TiO}_{2}-\mathrm{CNTs}$ composites were measured by a mechanical test machine (Instron 3366, USA) according to the standard GB/T 528-2009. The friction test was performed on a friction test machine (UMT-TriboLab, Bruke USA), and the applied rotating speed and pressure were $1800 \mathrm{rpm}$ and $500 \mathrm{~N}$ during the friction time of $30 \mathrm{~s}$, respectively. Rebound resilience property, hardness, and abrasion tests of the $\mathrm{NR}$ and $\mathrm{NR} / \mathrm{TiO}_{2}-$ CNTs composites were measured according to the standard GB/T 1681, GB/T 9867, and GB/T 531, respectively. Compression recovery ratios of $\mathrm{NR}$ and $\mathrm{NR} / \mathrm{TiO}_{2}-\mathrm{CNTs}$ composites were obtained according to $\mathrm{GB} / \mathrm{T}$ 7759, and the compression set, compression time, and temperature were $25 \%, 24 \mathrm{~h}$, and $100{ }^{\circ} \mathrm{C}$, respectively. An infrared thermal imager (FTLR T420) was used to track the temperature at the surface of the samples. The surface morphology was examined by a scanning electron microscopy (SEM) (JEOL JSM 5900LV, Japan) and a Karl Zeiss LSM 800 Confocal Microscope (LSM800 Carl Zeiss Germany). In the SEM test, the used accelerating voltage was $10 \mathrm{kV}$. An X-ray energy dispersion spectrum (EDX) analyzer (Inca Penta-Fetx3 Oxford, USA) was used to measure the element contents of different samples. Transmission electron microscopy (TEM, model H-800, Hitachi, Japan) of the nanoparticles was completed at an accelerating voltage of $200 \mathrm{kV}$. FTIR spectra in the range of 4000$400 \mathrm{~cm}^{-1}$ were recorded using a Nicolet 6700 spectrometer (Thermo Fisher Scientific, USA). X-ray diffraction (XRD) patterns were recorded by a DX-1000 X-ray diffractometer (PANalytical B.V., Holland) in the $2 \theta$ range of $5-80^{\circ}$ using $\mathrm{Cu}-\mathrm{K} \alpha$ radiation $(\lambda=1.542 \AA)$. A SPEX Raman apparatus (1403, USA) was used to record the laser Raman spectroscopy (LRS) in the scanning range of $500-2200 \mathrm{~cm}^{-1}$ using the excitation wavelength of $532 \mathrm{~nm}$.

\section{Results and discussion}

\subsection{Structural characterization of $\mathrm{TiO}_{2}-\mathrm{CNTS}$}

The SEM micrographs of CNTs, $\mathrm{TiO}_{2}$, and $\mathrm{TiO}_{2}-\mathrm{CNTs}$ are shown in Fig. 1. The surface of the CNTs is quite smooth. From
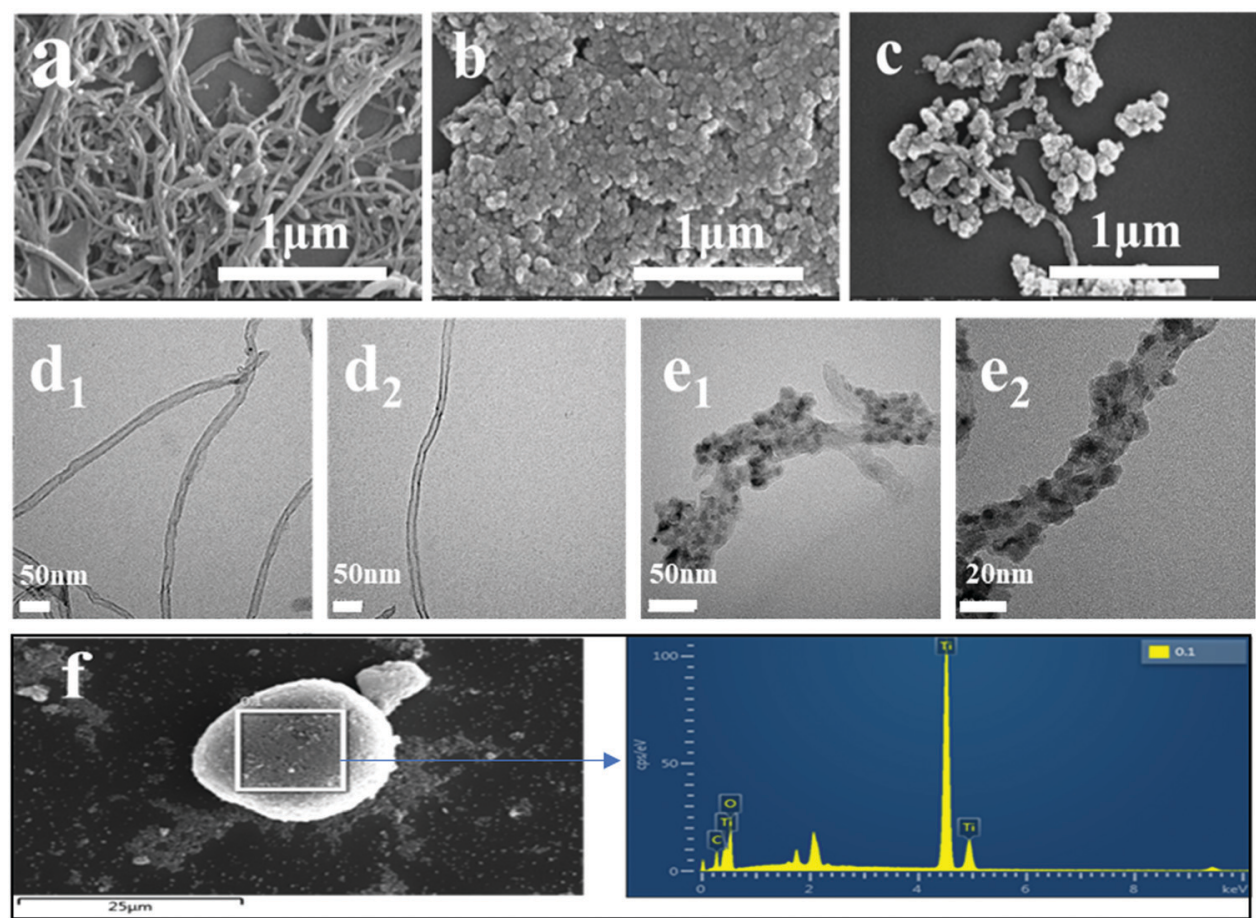

Fig. 1 SEM micrographs of CNTs (a), $\mathrm{TiO}_{2}$ (b), and TiO $2-C N T s$ (c); TEM micrographs of CNTs $\left(\mathrm{d}_{1}\right.$ and $\left.d_{2}\right)$ and TiO ${ }_{2}-C N T s\left(e_{1}\right.$ and $\left.e_{2}\right)$; EDX spectra of $\mathrm{TiO}_{2}$-CNTs (f). 


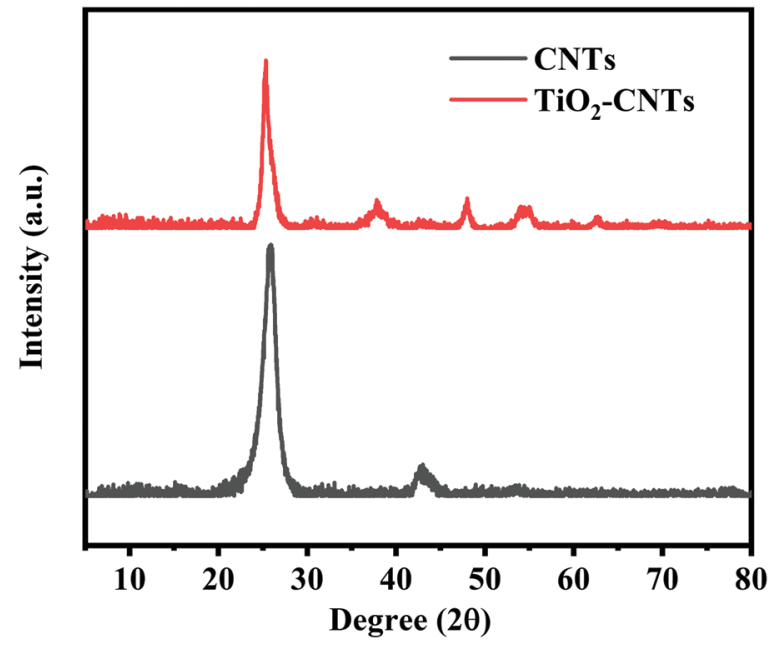

Fig. 2 XRD patterns of CNTs and $\mathrm{TiO}_{2}-\mathrm{CNTS}$.

Fig. $1 \mathrm{~b}$, it can be observed that there are many $\mathrm{TiO}_{2}$ particles and these particles agglomerate together. After hybridizing with CNTs using $\mathrm{TiO}_{2}$, many small $\mathrm{TiO}_{2}$ particles adhere at the surface of the CNTs and some of them also aggregate at the outer wall. To clearly illustrate the microstructure, the TEM test was used to further analyze the CNTs and $\mathrm{TiO}_{2}$-CNTs. Fig. 1d shows that the surface of the CNTs is very smooth, which is consistent with that shown in Fig. 1a. For the $\mathrm{TiO}_{2}-\mathrm{CNTs}$, the tubular structure can be clearly seen, for which the inner tube is the CNTs and outer particles are $\mathrm{TiO}_{2}$. From the SEM and TEM results, it was revealed that $\mathrm{TiO}_{2}$ particles were formed at the surface of the CNTs via a dehydration condensation process. In addition, EDX was performed to determine the component of $\mathrm{TiO}_{2}$-CNTs. According to Fig. 1f, the $\mathrm{TiO}_{2}-\mathrm{CNTs}$ mainly consist of $\mathrm{C}, \mathrm{O}$, and Ti elements, which further illustrates that the hybrid $\mathrm{TiO}_{2}-\mathrm{CNTs}$ was formed.

The prepared $\mathrm{TiO}_{2}-\mathrm{CNTs}$ were further characterized by XRD. The result is shown in Fig. 2. For CNTs, the diffraction peak at $2 \theta=26^{\circ}$ is ascribed to their (002) reflection. When the CNTs are hybridized by $\mathrm{TiO}_{2}$, several new peaks appear at $2 \theta=25.2^{\circ}$, $37.8^{\circ}, 48.1^{\circ}, 53.9^{\circ}, 55.1^{\circ}$, and $62.7^{\circ}$ besides those ascribed to CNTs, which correspond to (101), (004), (200), (105), (211), and (204) crystal planes of anatase $\mathrm{TiO}_{2} \cdot{ }^{17}$ The XRD result indicates that the crystalline structures of both $\mathrm{TiO}_{2}$ and CNTs were not affected by the hybridization reaction between them. In order to further illustrate the structure of the $\mathrm{TiO}_{2}-\mathrm{CNTs}$, Raman spectroscopy was performed for the CNTs and $\mathrm{TiO}_{2}-\mathrm{CNTs}$. The results are shown in Fig. 3. In the Raman spectra, two absorption peaks located at about 1342 and $1576 \mathrm{~cm}^{-1}$ correspond to the D and G
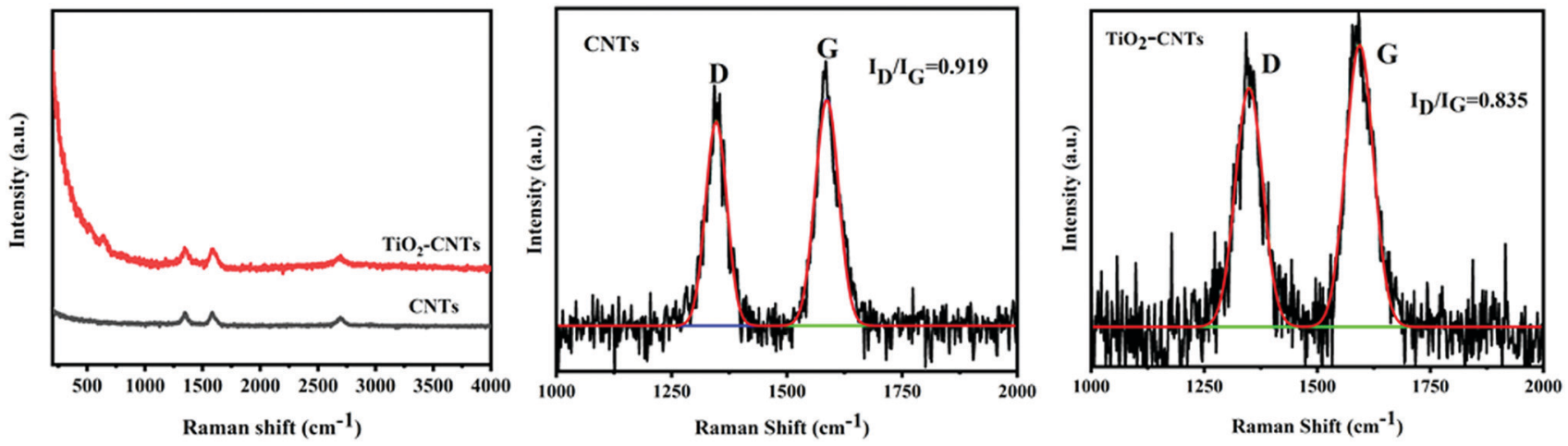

Fig. 3 Raman spectra of CNTs and $\mathrm{TiO}_{2}$-CNTs.
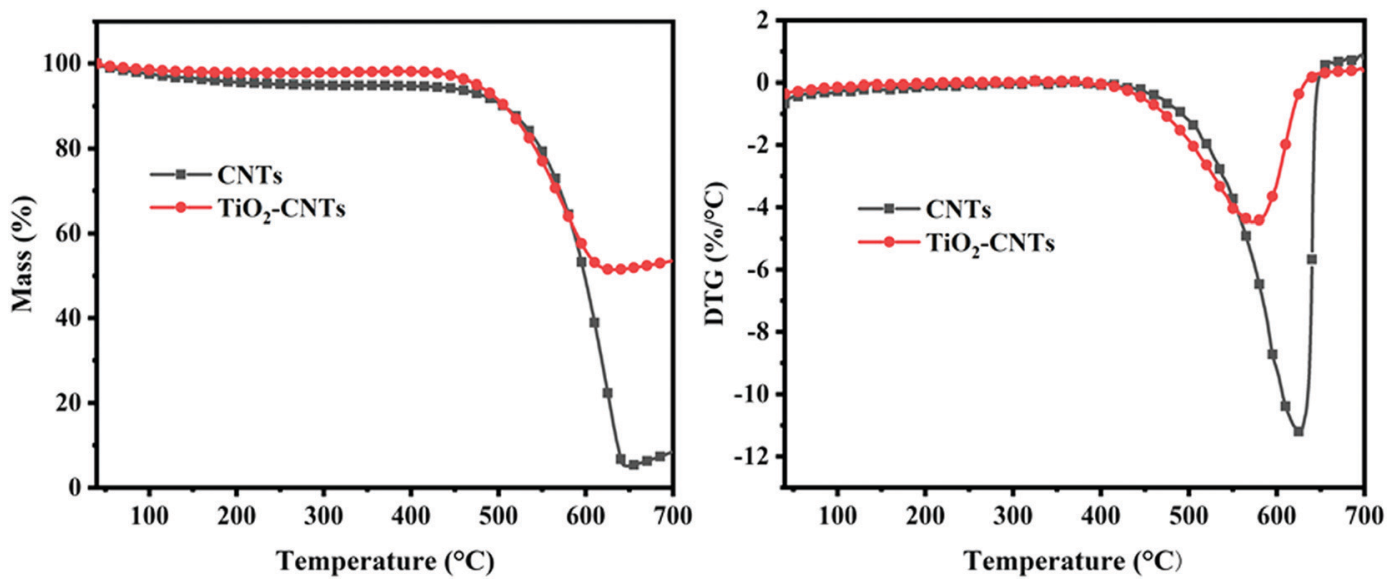

Fig. 4 TG (a) and DTG (b) results of CNTs and $\mathrm{TiO}_{2}-\mathrm{CNTs}$. 

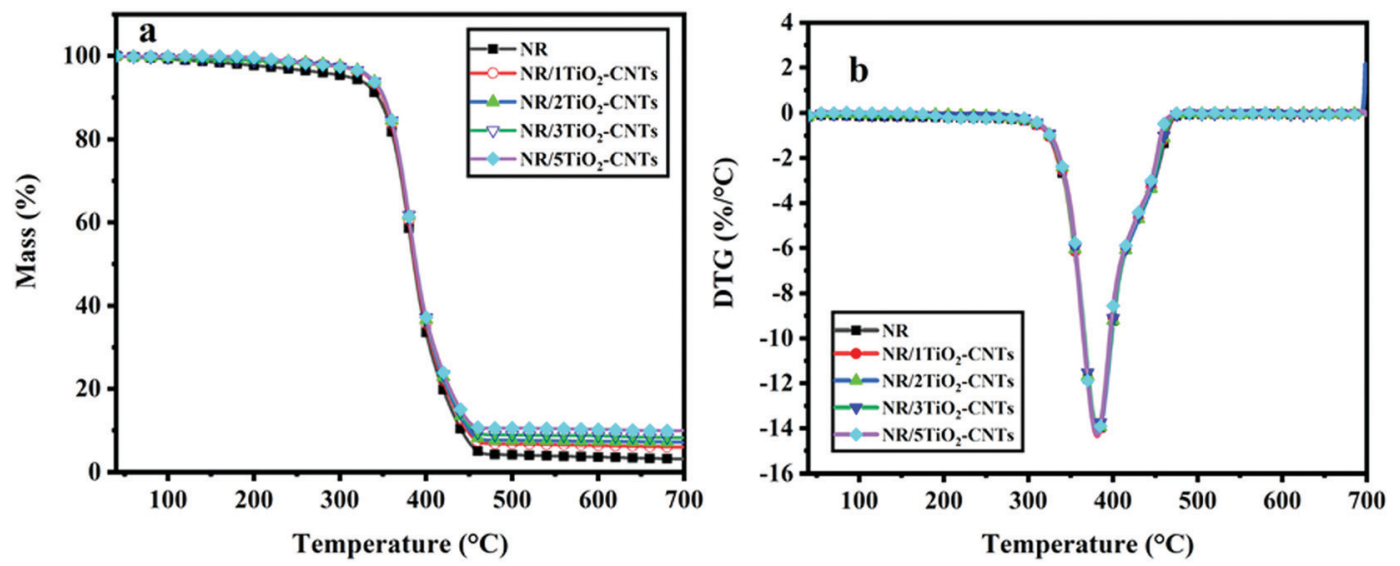

Fig. 5 TG (a) and DTG (b) curves of the NR/TiO $2-C N T s$ composites in $\mathrm{N}_{2}$ atmosphere.

bands of graphitized carbon, respectively. ${ }^{18}$ The intensity ratio of the $\mathrm{D}$ to $\mathrm{G}$ bands $\left(I_{\mathrm{D}} / I_{\mathrm{G}}\right)$ can be used to characterize the change in the defect degree of the CNTs. The $I_{\mathrm{D}} / I_{\mathrm{G}}$ for CNTs is 0.919 , which is only slightly higher than 0.835 for $\mathrm{TiO}_{2}-\mathrm{CNTs}$, showing no significant change in the graphitization degree of the CNTs. Clearly, the graphitization of CNTs was not remarkably affected by the hybridization reaction with $\mathrm{TiO}_{2}$.

\subsection{Thermal properties of $\mathbf{C N T s}$ and $\mathbf{T i O}_{2}$-CNTs}

TGA was used to further characterize the thermal properties of $\mathrm{TiO}_{2}-\mathrm{CNTs}$. The result is shown in Fig. 4. As a comparison, CNTs were also analyzed by TGA. Both $\mathrm{TiO}_{2}-\mathrm{CNTs}$ and CNTs show only one decomposition stage from 40 to $700{ }^{\circ} \mathrm{C}$ under air atmosphere and their initial decomposition temperatures have no apparent difference. For the CNTs, the residue at $700{ }^{\circ} \mathrm{C}$ is significantly lower than that of the $\mathrm{TiO}_{2}-\mathrm{CNTs}$, which should be due to the oxidation of CNTs. For the $\mathrm{TiO}_{2}-\mathrm{CNTs}$, the initial

Table 2 Detailed TG data of the NR/TiO $2-C N T s$ composites in $\mathrm{N}_{2}$ atmosphere

\begin{tabular}{llllc}
\hline Samples & $T_{5 \%}\left({ }^{\circ} \mathrm{C}\right)$ & $T_{\max }\left({ }^{\circ} \mathrm{C}\right)$ & $\operatorname{MLR}_{\max }\left(\% /{ }^{\circ} \mathrm{C}\right)$ & Residue $(\%)$ \\
\hline $\mathrm{NR}$ & 308.8 & 381.4 & 14.3 & 3.2 \\
$\mathrm{NR} / 1 \mathrm{TiO}_{2}-\mathrm{CNTs}$ & 332.1 & 381.1 & 14.3 & 6.0 \\
$\mathrm{NR} / 2 \mathrm{TiO}_{2}-\mathrm{CNTs}$ & 334.4 & 381.6 & 14.2 & 7.2 \\
$\mathrm{NR} / 3 \mathrm{TiO}_{2}-\mathrm{CNTs}$ & 334.3 & 381.5 & 14.0 & 8.3 \\
$\mathrm{NR} / 5 \mathrm{TiO}_{2}-\mathrm{CNTs}$ & 333.7 & 381.1 & 14.3 & 10.0
\end{tabular}

decomposition temperature is close to that of the CNTs. However, the residual mass of the $\mathrm{TiO}_{2}-\mathrm{CNTs}$ is significantly higher than that of the CNTs, which is mainly due to the high residual mass of $\mathrm{TiO}_{2}$ at high temperature. ${ }^{16}$ Here, the mass percentage plot of CNT shows an upside trend after $650{ }^{\circ} \mathrm{C}$, which should be due to the unstable gas flow after $650{ }^{\circ} \mathrm{C}$. Obviously, the prepared $\mathrm{TiO}_{2}$-CNTs possess high thermal stability.

\subsection{Thermal properties of the $\mathrm{NR} / \mathrm{TiO}_{2}-\mathrm{CNT}$ composites}

The TGA results of different $\mathrm{NR} / \mathrm{TiO}_{2}-\mathrm{CNTs}$ composites are shown in Fig. 5 and Table 2. The $T_{5 \%}$ and $T_{\max }$ are the decomposition temperature at $5 \mathrm{wt} \%$ mass loss and the decomposition temperature at the maximum mass loss rate, respectively. $\mathrm{MLR}_{\max }$ is the maximum mass loss rate. In nitrogen atmosphere, the initial decomposition temperature of $\mathrm{NR} / 1 \mathrm{TiO}_{2}-\mathrm{CNTs}$ is $332.1{ }^{\circ} \mathrm{C}$, which increased by $24{ }^{\circ} \mathrm{C}$ compared with that of NR. Clearly, a small amount of $\mathrm{TiO}_{2}$-CNTs significantly improved the thermal stability of NR. The initial decomposition temperature of the $\mathrm{NR} / \mathrm{TiO}_{2}-\mathrm{CNTs}$ gradually increases on raising the content of $\mathrm{TiO}_{2}-\mathrm{CNTs}$. However, the change in the temperature increase is quite low with increasing $\mathrm{TiO}_{2}$-CNTs content from 1 to 5 phr. According to previous studies, ${ }^{19-21}$ it can be concluded that the increase in the initial decomposition temperature of NR after the incorporation of the $\mathrm{TiO}_{2}$-CNTs should mainly be attributed to the thermal conductivity and physical isolation of
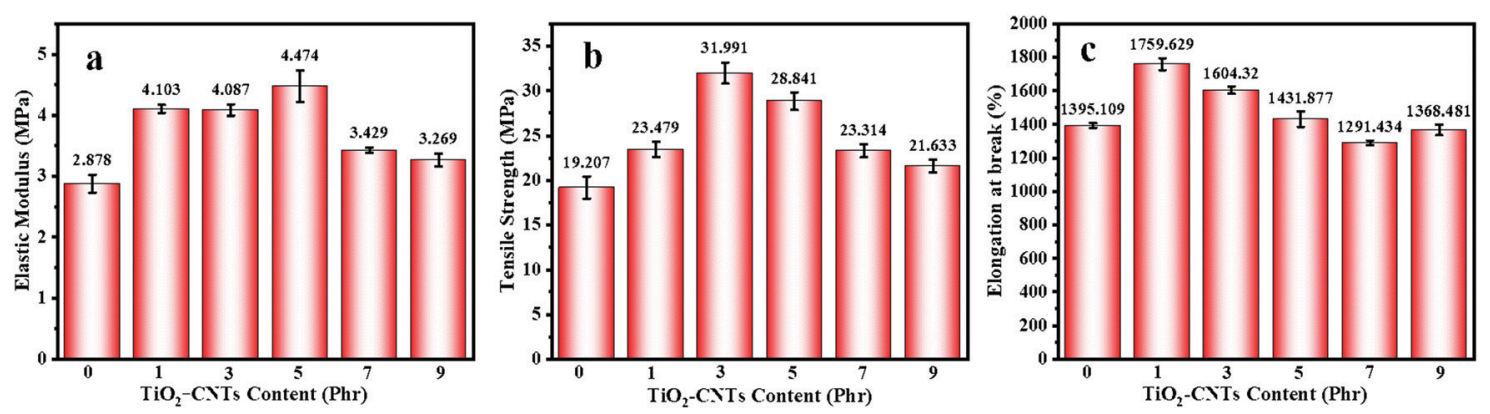

Fig. 6 Mechanical properties of NR and the $\mathrm{NR} / \mathrm{TiO}_{2}-\mathrm{CNTs}$ composites: elastic modulus (a), tensile strength (b), and elongation at break (c). 
Table 3 The hardness, rebound resilience, abrasion, and compression properties of the composites

\begin{tabular}{|c|c|c|c|c|c|}
\hline Samples & NR & $\mathrm{NR} / 1 \mathrm{TiO}_{2}-\mathrm{CNTs}$ & $\mathrm{NR} / 2 \mathrm{TiO}_{2}-\mathrm{CNTs}$ & $\mathrm{NR} / 3 \mathrm{TiO}_{2}-\mathrm{CNTs}$ & $\mathrm{NR} / 5 \mathrm{TiO}_{2}-\mathrm{CNTS}$ \\
\hline Abrasion index (\%) & $132.5 \pm 31.1$ & $129.6 \pm 10.2$ & $125.5 \pm 2.8$ & $143.1 \pm 15.7$ & $158.6 \pm 31.6$ \\
\hline rebound resilience (\%) & $62.3 \pm 0.9$ & $65.9 \pm 0.5$ & $66.9 \pm 0.2$ & $71.2 \pm 1.2$ & $71.5 \pm 0.5$ \\
\hline Compression recovery ratio (\%) & $59.9 \pm 4.2$ & $56.1 \pm 0.8$ & $63.1 \pm 2.9$ & $60.3 \pm 3.7$ & $59.3 \pm 1.6$ \\
\hline Hardness (HA) & $36.6 \pm 1.2$ & $39.2 \pm 0.8$ & $40.2 \pm 2.1$ & $40.9 \pm 2.3$ & $40.6 \pm 1.5$ \\
\hline
\end{tabular}

the $\mathrm{TiO}_{2}$-CNTs. At $700{ }^{\circ} \mathrm{C}$, the residual mass of the $\mathrm{NR} / \mathrm{TiO}_{2}-$ CNTs containing 1-5 phr $\mathrm{TiO}_{2}-\mathrm{CNTs}$ is higher than that of NR, which should be due to the higher residual mass of $\mathrm{TiO}_{2}-\mathrm{CNTs}$ than that of NR. In addition, the decomposition rates of the $\mathrm{NR} / \mathrm{TiO}_{2}-\mathrm{CNTs}$ composites at the maximum decomposition temperature have no apparent change compared with that of NR. In air atmosphere, both the $\mathrm{NR} / \mathrm{TiO}_{2}-\mathrm{CNT}$ composite and NR show two decomposition stages. For them, the additional decomposition at about $550{ }^{\circ} \mathrm{C}$ is ascribed to the change in the hydrocarbons. ${ }^{7,22,23}$ However, both the NR/TiO ${ }_{2}-\mathrm{CNTs}$ composites and NR show no an apparent difference in the thermal stability in this case.

\subsection{Mechanical properties of the $\mathrm{NR} / \mathrm{TiO}_{2}-\mathrm{CNTs}$ composites}

The elastic modulus at break, tensile strength, and elongation at break for the $\mathrm{NR}$ and $\mathrm{NR} / \mathrm{TiO}_{2}-\mathrm{CNT}$ composites are shown in Fig. 6. Basically, these properties for all the $\mathrm{NR} / \mathrm{TiO}_{2}-\mathrm{CNTS}$ composites containing $1,2,3$, and 5 phr $\mathrm{TiO}_{2}-\mathrm{CNTs}$ are superior to those of the NR composites and all of them firstly increase to a maximum value and then decrease, showing a similar change trend on raising the content of the $\mathrm{TiO}_{2}-\mathrm{CNTs}$. For the NR

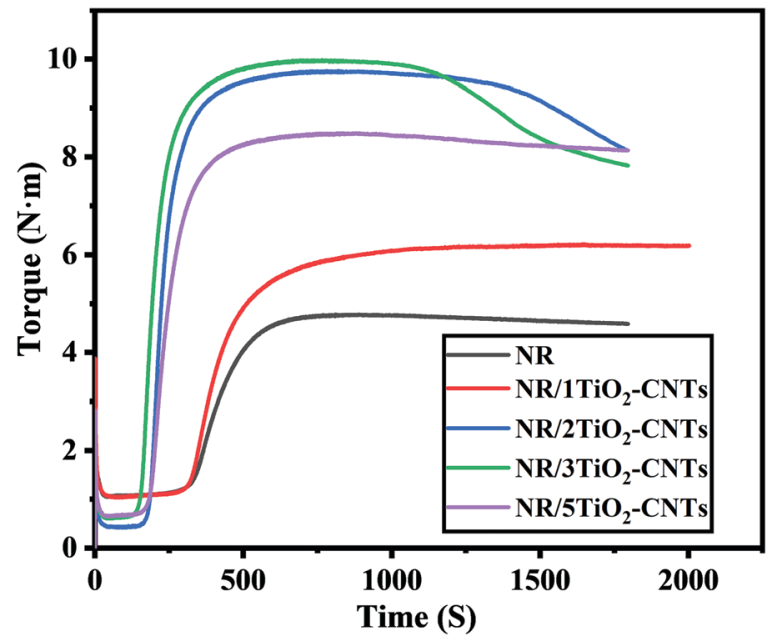

Fig. 7 Vulcanization properties of different $\mathrm{NR} / \mathrm{TiO}_{2}-\mathrm{CNTs}$ composites. composite, the elastic modulus, tensile strength, and elongation at break are 2.9 MPa, 19.2 MPa, and $1395.1 \%$, respectively. When the content of $\mathrm{TiO}_{2}-\mathrm{CNTs}$ is $3 \mathrm{phr}$, these parameters for NR/ $3 \mathrm{TiO}_{2}-\mathrm{CNTs}$ reach 4.1 MPa, 32.0 $\mathrm{MPa}$, and $1604.1 \%$, respectively, which correspondingly increased by $41.4 \%, 66.7 \%$, and $15.0 \%$. In this case, the tensile strength of the NR/3TiO - CNTs almost reaches the maximum value, which is equivalent to the strength of 50 phr carbon black-filled NR composite (about 32.0 MPa in our experiment). The elongation at break for the $\mathrm{NR} / 1 \mathrm{TiO}_{2}-\mathrm{CNTs}$ and the elastic modulus for the $\mathrm{NR} / 5 \mathrm{TiO}_{2}-\mathrm{CNTs}$ are slightly higher than the corresponding values of other $\mathrm{NR} / \mathrm{TiO}_{2}-\mathrm{CNTs}$ composites in the $\mathrm{TiO}_{2}-\mathrm{CNTs}$ range from 0 to $9 \mathrm{phr}$, respectively. Clearly, the $\mathrm{TiO}_{2}-\mathrm{CNTs}$ is an ideal reinforcing agent for NR and a small amount of $\mathrm{TiO}_{2}-\mathrm{CNTs}$ may significantly enhance the mechanical properties of NR.

\subsection{Rebound resilience, abrasion, compression properties, and hardness}

Table 3 shows that the hardness and rebound resilience of NR increase slightly after the incorporation of the $\mathrm{TiO}_{2}-\mathrm{CNTs}$. When the content of $\mathrm{TiO}_{2}-\mathrm{CNTs}$ is $5 \mathrm{phr}$, the hardness and rebound resilience of $\mathrm{NR} / 5 \mathrm{TiO}_{2}-\mathrm{CNTs}$ are raised to $40.6 \mathrm{HA}$ and $71.5 \%$, respectively. For the compression recovery ratio, there is no apparent change on increasing the $\mathrm{TiO}_{2}-\mathrm{CNTs}$ from 1 to $5 \mathrm{phr}$ compared with that of NR. As for the abrasion property, it can be found that the abrasion indexes of the NR composites show a slight fluctuation in comparison with that of NR when there is only 1 and 2 phr $\mathrm{TiO}_{2}-\mathrm{CNTs}$. On increasing the $\mathrm{TiO}_{2}-\mathrm{CNTs}$ to 3 and $5 \mathrm{phr}$, the abrasion indexes of $\mathrm{NR} / 3 \mathrm{TiO}_{2}-\mathrm{CNTs}$ reach 143.1 and $158.6 \%$, respectively. Clearly, the $\mathrm{TiO}_{2}-\mathrm{CNTs}$ have different influences on the rebound resilience, abrasion, compression properties, and hardness of NR.

\subsection{The vulcanization properties of the $\mathrm{NR} / \mathrm{TiO}_{2}-\mathrm{CNTs}$ composites}

The vulcanization properties of different NR/TiO ${ }_{2}-\mathrm{CNTs}$ composites are shown in Fig. 7. Compared to the NR composite, the addition of $\mathrm{TiO}_{2}-\mathrm{CNTs}$ increases the torque of the composite to some extent, suggesting that $\mathrm{TiO}_{2}-\mathrm{CNTs}$ efficiently increased the
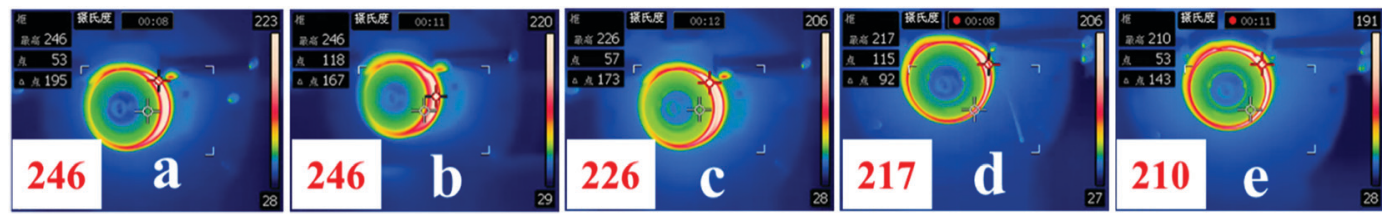

Fig. 8 The maximum temperatures at the surfaces of NR (a), NR/1TiO $2-C N T s$ (b), NR/2TiO $2-C N T s$ (c), NR/3TiO $2-C N T s$ (d), and NR/5TiO $2-C N T s$ (e) during the friction test. 
crosslink density of the composites. Here, the increased crosslink density is mainly ascribed to the physical crosslinking caused by the nanoparticles. When the addition amount of $\mathrm{TiO}_{2}-\mathrm{CNTs}$ is 3 or $5 \mathrm{phr}$, the torque of the composite decreases slightly, which should be attributed to the aggregation of $\mathrm{TiO}_{2}-$ CNTs in the matrix.

\subsection{Stability of the $\mathrm{NR} / \mathrm{TiO}_{2}-\mathrm{CNTs}$ composites under extreme friction condition}

The temperature change at the friction surface of the $\mathrm{NR} / \mathrm{TiO}_{2}-$ CNTs composites was observed by an infrared thermal imager. Fig. 8 shows the highest temperature of the friction surface of the $\mathrm{NR} / \mathrm{TiO}_{2}-\mathrm{CNTs}$ composites in $30 \mathrm{~s}$ during the friction test. Here, it should be noted that the friction test was performed in the presence of $50 \mathrm{phr}$ carbon black in the NR composite. The maximum temperature at the friction surfaces of NR and NR/ $1 \mathrm{TiO}_{2}-\mathrm{CNTs}$ are $246{ }^{\circ} \mathrm{C}$ but the maximum temperatures at the friction surfaces of $\mathrm{NR} / 3 \mathrm{TiO}_{2}-\mathrm{CNTs}$ and $\mathrm{NR} / 5 \mathrm{TiO}_{2}-\mathrm{CNTs}$ decrease compared with that of $\mathrm{NR}$, which are $217{ }^{\circ} \mathrm{C}$ and $210{ }^{\circ} \mathrm{C}$, respectively, which correspondingly decreased by 29 and $36{ }^{\circ} \mathrm{C}$ compared with that at the surface of NR. However, there is no apparent change in the friction time to reach the maximum temperature at the friction surface between NR and the $\mathrm{NR} / \mathrm{TiO}_{2}-\mathrm{CNTs}$ composites. The above experimental results showed that a small amount of $\mathrm{TiO}_{2}-\mathrm{CNTs}$ reduced the temperature peak at the friction surface of $\mathrm{NR}$, which remarkably enhanced the stability of the tread of the aircraft tires when experiencing the extreme friction condition.

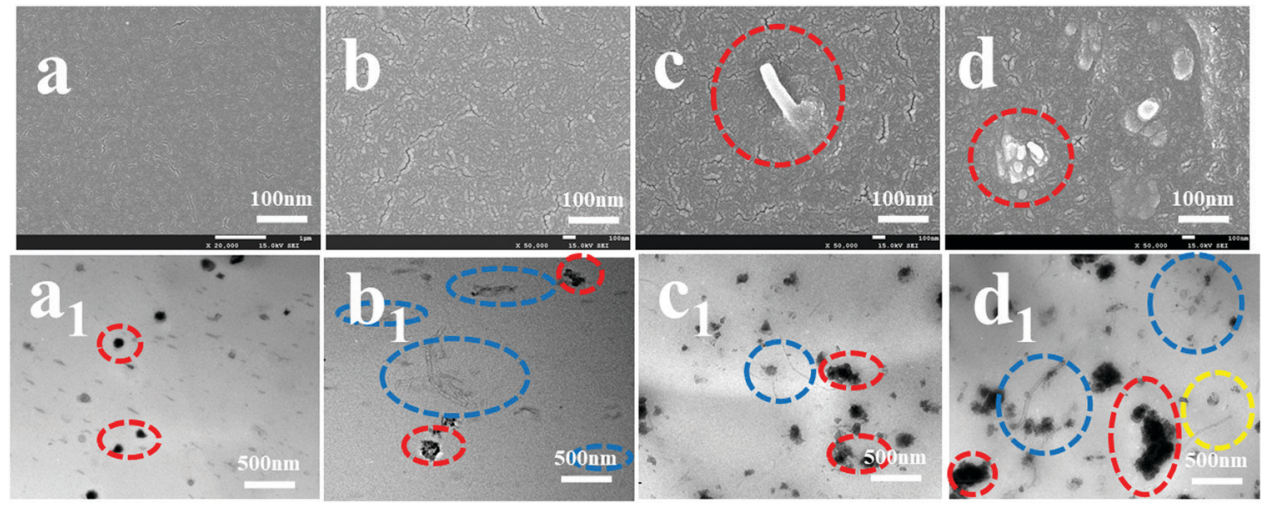

Fig. 9 SEM and TEM micrographs of NR and the NR/TiO $2-C N T s$ composites: NR ( $a$ and $\left.a_{1}\right), N R / 1 T i O_{2}-C N T s\left(b\right.$ and $\left.b_{1}\right), N R / 3 T i O_{2}-C N T s\left(c\right.$ and $\left.c_{1}\right), N R /$ $5 \mathrm{TiO}_{2}-\mathrm{CNTs}$ ( $d$ and $\mathrm{d}_{1}$ ).
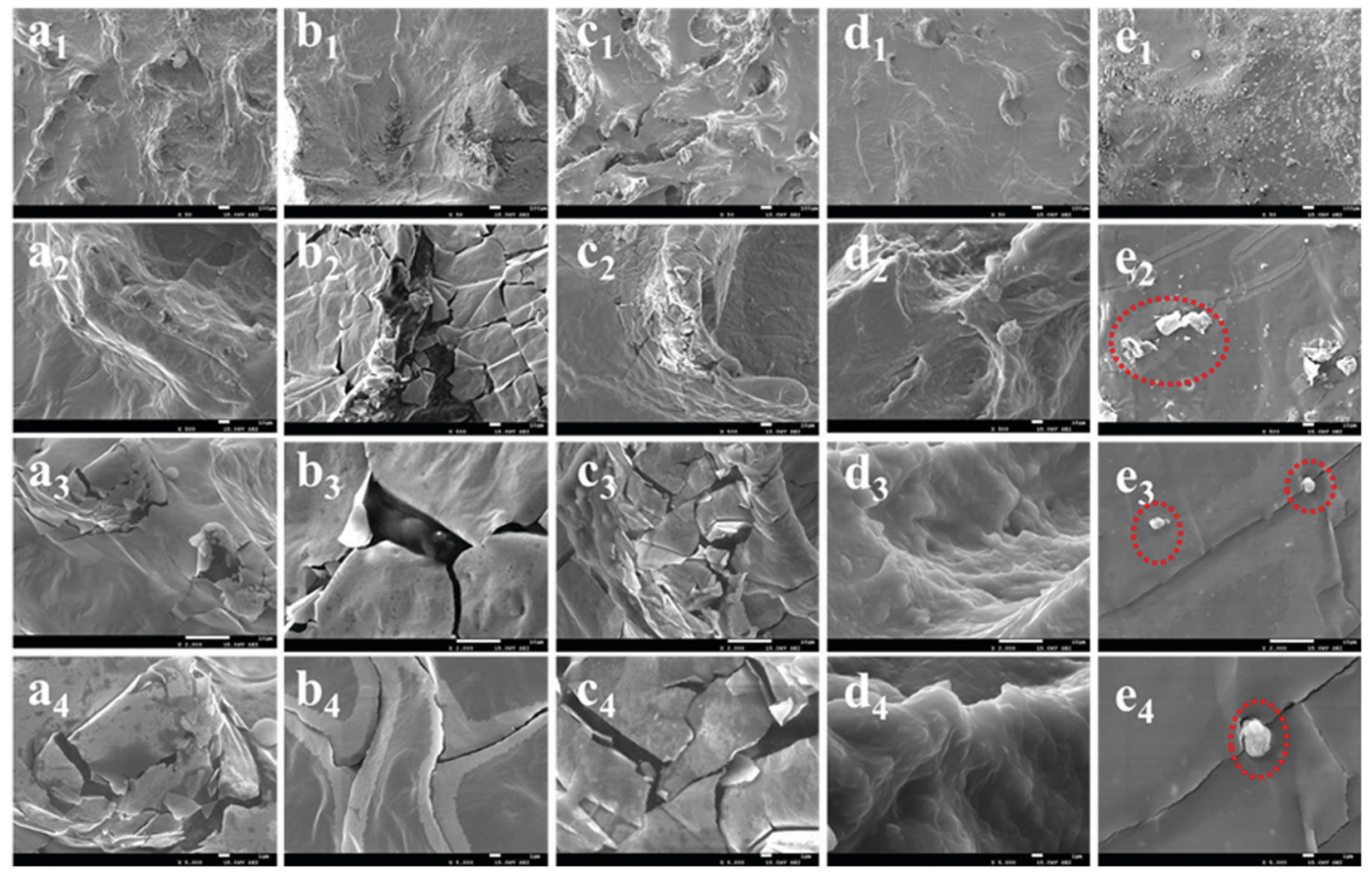

Fig. 10 SEM micrographs at the friction surfaces of NR $\left(a_{1}-a_{4}\right), N R / 1 T i O_{2}-C N T s\left(b_{1}-b_{4}\right), N R / 2 T i O_{2}-C N T s\left(c_{1}-c_{4}\right), N R / 3 T i O_{2}-C N T s\left(d_{1}-d_{4}\right)$, and NR/ $5 \mathrm{TiO}_{2}-\mathrm{CNTS}\left(\mathrm{e}_{1}-\mathrm{e}_{4}\right)$. 


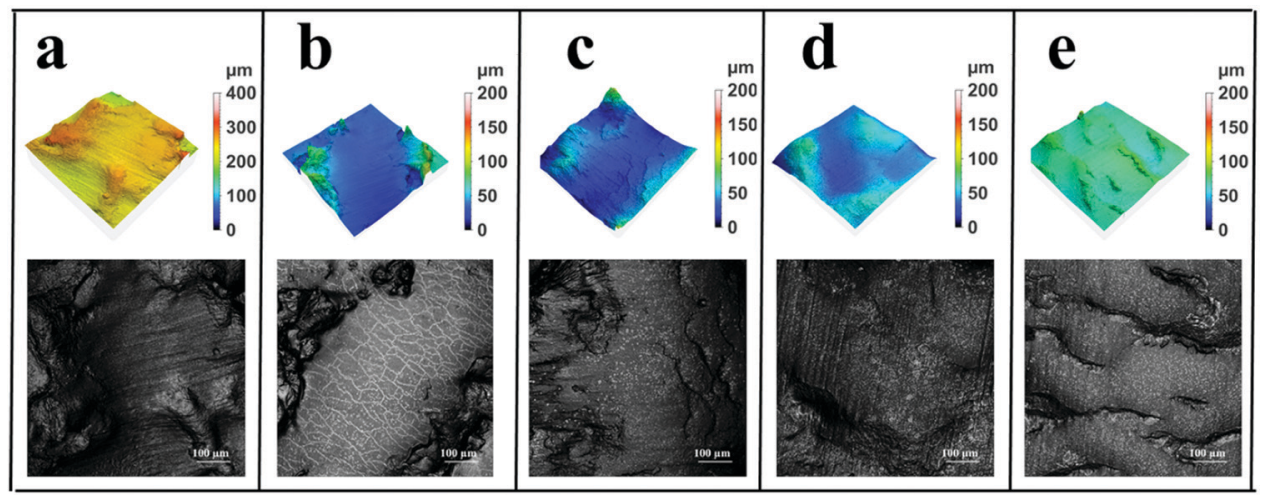

Fig. 11 Confocal microscope pictures of the friction surfaces of $\mathrm{NR}$ (a), NR/1TiO $2-C N T s$ (b), NR/2TiO $2-C N T s(c), N R / 3 T i O_{2}-C N T s(d)$, and NR/5TiO $2-$ CNTs (e).

Here, a low heat signature was detected on the surface of the $\mathrm{NR} / \mathrm{TiO}_{2}-\mathrm{CNTs}$ composites, which should mainly be due to the reduction of surface friction or the higher thermal conductivity. Of course, the thermal stability of the $\mathrm{NR} / \mathrm{TiO}_{2}-$ CNTs composites also plays a role in decreasing the surface temperature.

\subsection{Mechanism of mechanical enhancement and the improved stability}

First, the brittle-fractured surfaces of the $\mathrm{NR}$ and $\mathrm{NR} / \mathrm{TiO}_{2}-$ CNTs composites were investigated by SEM, and the result is shown in Fig. 9. When the amount of $\mathrm{TiO}_{2}-\mathrm{CNTs}$ is $3 \mathrm{phr}$, the bulge of a single nanotube can be seen locally, which should be caused by the insertion of the nanotubes. At $3 \mathrm{phr} \mathrm{TiO}_{2}$-CNTs in NR, micro-aggregation of the nanotubes appears. In order to more directly observe the dispersion of $\mathrm{TiO}_{2}-\mathrm{CNTs}$ in the NR substrate, TEM was performed for NR and the $\mathrm{NR} / \mathrm{TiO}_{2}-\mathrm{CNTs}$ composites. For NR, there are some black particles (marked by red ellipse), which should be from insoluble sulfur that is dispersed in the NR substrate. For the composites filled with different amounts of $\mathrm{TiO}_{2}-\mathrm{CNTs}$, nanotubes (marked by blue ellipse) can be clearly seen in the NR matrix. When the loading amount of $\mathrm{TiO}_{2}-\mathrm{CNTs}$ is $1 \mathrm{phr}$, the nanotubes do not agglomerate obviously and the dispersion of the $\mathrm{TiO}_{2}-\mathrm{CNTs}$ is very uniform. On increasing the $\mathrm{TiO}_{2}$-CNTs concentration to $3 \mathrm{phr}$, a slight agglomeration of the nanotubes is observed. When the content of $\mathrm{TiO}_{2}-\mathrm{CNTs}$ reaches $5 \mathrm{phr}$, some larger aggregates exist in the NR. These results indicate that it is very easy for $\mathrm{TiO}_{2}-\mathrm{CNTs}$ to agglomerate in the NR matrix when the amount of $\mathrm{TiO}_{2}-\mathrm{CNTs}$ is higher than $3 \mathrm{phr}$, which is an important reason that affects the mechanical properties.

Fig. 10 shows the SEM micrographs at the friction surfaces of the NR and NR/TiO ${ }_{2}$-CNTs composites after the friction test. The results show that there are obvious cavities at the friction surface of NR and there are some debris at the edge of the cavities. For the $\mathrm{NR} / 1 \mathrm{TiO}_{2}-\mathrm{CNTs}$ and $\mathrm{NR} / 2 \mathrm{TiO}_{2}-\mathrm{CNTs}$ composites, there are also some cavities and debris at the friction surfaces. However, no cavity or debris can be observed at the friction surface for $\mathrm{NR} / 3 \mathrm{TiO}_{2}-\mathrm{CNTs}$, the friction surface is continuous and dense, showing a toughness characteristic. At $5 \mathrm{phr} \mathrm{TiO}_{2}-\mathrm{CNTs}$, there are a small number of cracks at the surface of the $\mathrm{NR} / 5 \mathrm{TiO}_{2}-\mathrm{CNTs}$ composite. Moreover, some aggregates also exist at the surface, which should be related to the aggregation of the $\mathrm{TiO}_{2}-\mathrm{CNTs}$ and is consistent with the SEM result shown in Fig. 9. The analysis of the morphology of the friction surface demonstrated that the introduction of $\mathrm{TiO}_{2}-\mathrm{CNTs}$ affected the friction behavior of NR and reduced the damage of friction to the surface of NR, which should be an important reason for the improved stability of the $\mathrm{NR} / \mathrm{TiO}_{2}-\mathrm{CNTs}$ composites containing a small amount of $\mathrm{TiO}_{2}$-CNTs.

A confocal microscope was also used to analyze the friction surface of different rubber composites, and the morphologies and roughness data of different friction surfaces are respectively shown in Fig. 11 and Table 4. The result shows that the roughness of the friction surface decreases with the increase in $\mathrm{TiO}_{2}$-CNTs. When the contents of $\mathrm{TiO}_{2}-\mathrm{CNTs}$ are 3 and $5 \mathrm{phr}$, the roughness data at the corresponding friction surfaces are reduced to 8.2 and $3.8 \mu \mathrm{m}$, much lower than that of NR, which must be an important reason for the obvious decrease in the maximum temperature at the friction surfaces of $\mathrm{NR} / 3 \mathrm{TiO}_{2}-$ CNTs and NR/5TiO ${ }_{2}$-CNTs.

Fig. 12 shows the EDS result at the friction surfaces of NR and the $\mathrm{NR} / \mathrm{TiO}_{2}-\mathrm{CNTs}$ composites after the friction test. When $\mathrm{TiO}_{2}-\mathrm{CNTs}$ were incorporated into the NR, the relative contents of $\mathrm{C}, \mathrm{O}$, and $\mathrm{S}$ elements at the friction surface change significantly. The relative content of $\mathrm{S}$ element at the friction surface of $\mathrm{NR} / 1 \mathrm{TiO}_{2}-\mathrm{CNTs}, \mathrm{NR} / 2 \mathrm{TiO}_{2}-\mathrm{CNTs}$, or $\mathrm{NR} / 3 \mathrm{TiO}_{2}-\mathrm{CNTs}$ decreases compared with that of $\mathrm{NR}$, and the relative content of the $\mathrm{O}$ element also decreases, while the relative content of $\mathrm{C}$ increases in this case. It is worth noting that the relative content of $\mathrm{O}$ element at the friction surface of $\mathrm{NR} / 5 \mathrm{TiO}_{2}-\mathrm{CNTs}$ is relatively

Table 4 Roughness data at the friction surfaces of the $\mathrm{NR} / \mathrm{TiO}_{2}-\mathrm{CNTS}$ composites after the friction test

\begin{tabular}{lllll}
\hline Samples NR & $\begin{array}{l}\mathrm{NR} / 1 \mathrm{TiO}_{2}- \\
\mathrm{CNTs}\end{array}$ & $\begin{array}{l}\mathrm{NR} / 2 \mathrm{TiO}_{2}{ }^{-} \\
\mathrm{CNTs}\end{array}$ & $\begin{array}{l}\mathrm{NR} / 3 \mathrm{TiO}_{2}{ }^{-} \\
\mathrm{CNTs}\end{array}$ & $\begin{array}{l}\mathrm{NR} / 5 \mathrm{TiO}_{2-} \\
\mathrm{CNTs}\end{array}$ \\
\hline $\mathrm{Sa}^{a}(\mu \mathrm{m}) 13.3$ & 11.6 & 10.6 & 8.2 & 3.8
\end{tabular}

${ }^{a} \mathrm{Sa}$ is the index to evaluate the roughness. 

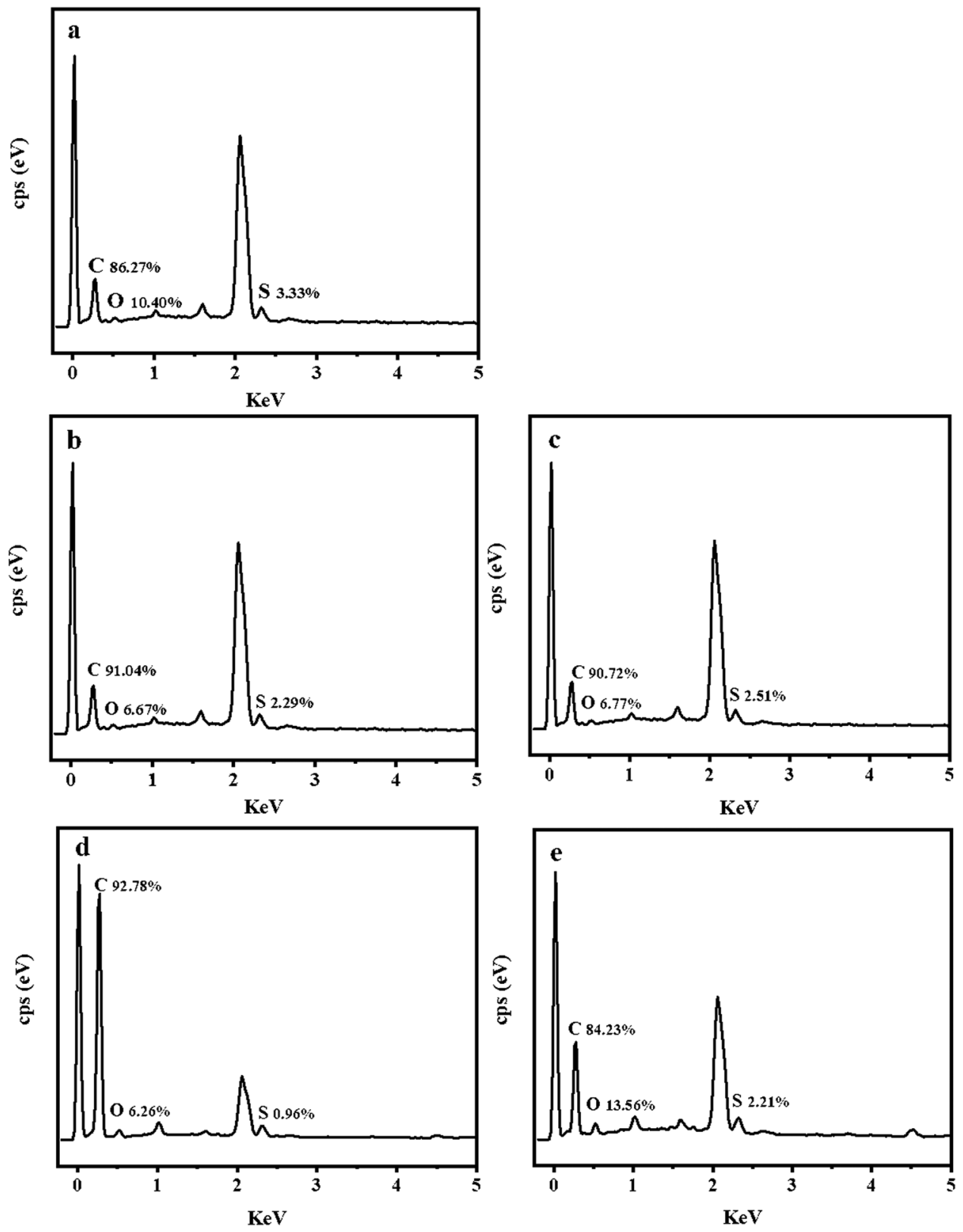

Fig. 12 EDS result at the friction surfaces of $\mathrm{NR}(\mathrm{a}), \mathrm{NR} / 1 \mathrm{TiO} \mathrm{O}_{2}-\mathrm{CNTs}$ (b), NR/2TiO $2-C N T s$ (c), NR/3TiO $\mathrm{T}_{2}-\mathrm{CNTs}(\mathrm{d})$, and NR/5TiO $2-\mathrm{CNTs}(\mathrm{e})$.

high, which should be caused by the presence of more $\mathrm{TiO}_{2}-$ CNTs at the surface, as illustrated in the SEM results shown in Fig. 9 and 10. On the basis of less $\mathrm{O}$ element and more $\mathrm{C}$ element at the friction surfaces of $\mathrm{NR} / 1 \mathrm{TiO}_{2}-\mathrm{CNTs}, \mathrm{NR} / 2 \mathrm{TiO}_{2}-\mathrm{CNTs}$, and $\mathrm{NR} / 3 \mathrm{TiO}_{2}-\mathrm{CNTs}$ composites, it can be concluded that the damage of friction to the crosslinking network of NR was reduced when a small amount of $\mathrm{TiO}_{2}-\mathrm{CNTs}$ were incorporated into the NR, further illustrating that a small amount of $\mathrm{TiO}_{2}-$ CNTs promoted the stability of NR under the intensive friction condition.

In order to further study the stability of the $\mathrm{NR} / \mathrm{TiO}_{2}-\mathrm{CNTs}$ composites, LRS test was used to study the difference in the graphitization degree at the friction surface for NR and the NR/ $\mathrm{TiO}_{2}-\mathrm{CNTs}$ composites. The result is shown in Fig. 13. For NR, the $I_{\mathrm{D}} / I_{\mathrm{G}}$ value of the material at the friction surface is 5.85 . After the incorporation of $1 \mathrm{phr} \mathrm{TiO}_{2}-\mathrm{CNTs}$, the $I_{\mathrm{D}} / I_{\mathrm{G}}$ value decreases slightly. With the increase in the $\mathrm{TiO}_{2}-\mathrm{CNTs}$, the $I_{\mathrm{D}} /$ $I_{\mathrm{G}}$ value at the surface of the $\mathrm{NR} / \mathrm{TiO}_{2}-\mathrm{CNTs}$ composites decreases gradually and is greatly reduced to 3.85 when $\mathrm{TiO}_{2}-$ CNTs is $5 \mathrm{phr}$, which is significantly lower than that of NR, indicating that the $\mathrm{TiO}_{2}-\mathrm{CNTs}$ promoted the graphitization degree at the friction surface of NR during the friction test. The graphitization degree at the friction surface can protect the internal substrate more effectively and prevent the erosion of heat and oxygen. Consequently, a small amount of $\mathrm{TiO}_{2}-\mathrm{CNTs}$ made a positive contribution to the stability of the $\mathrm{NR} / \mathrm{TiO}_{2}-$ CNTs composites by promoting the graphitization degree at the friction surface of NR. 

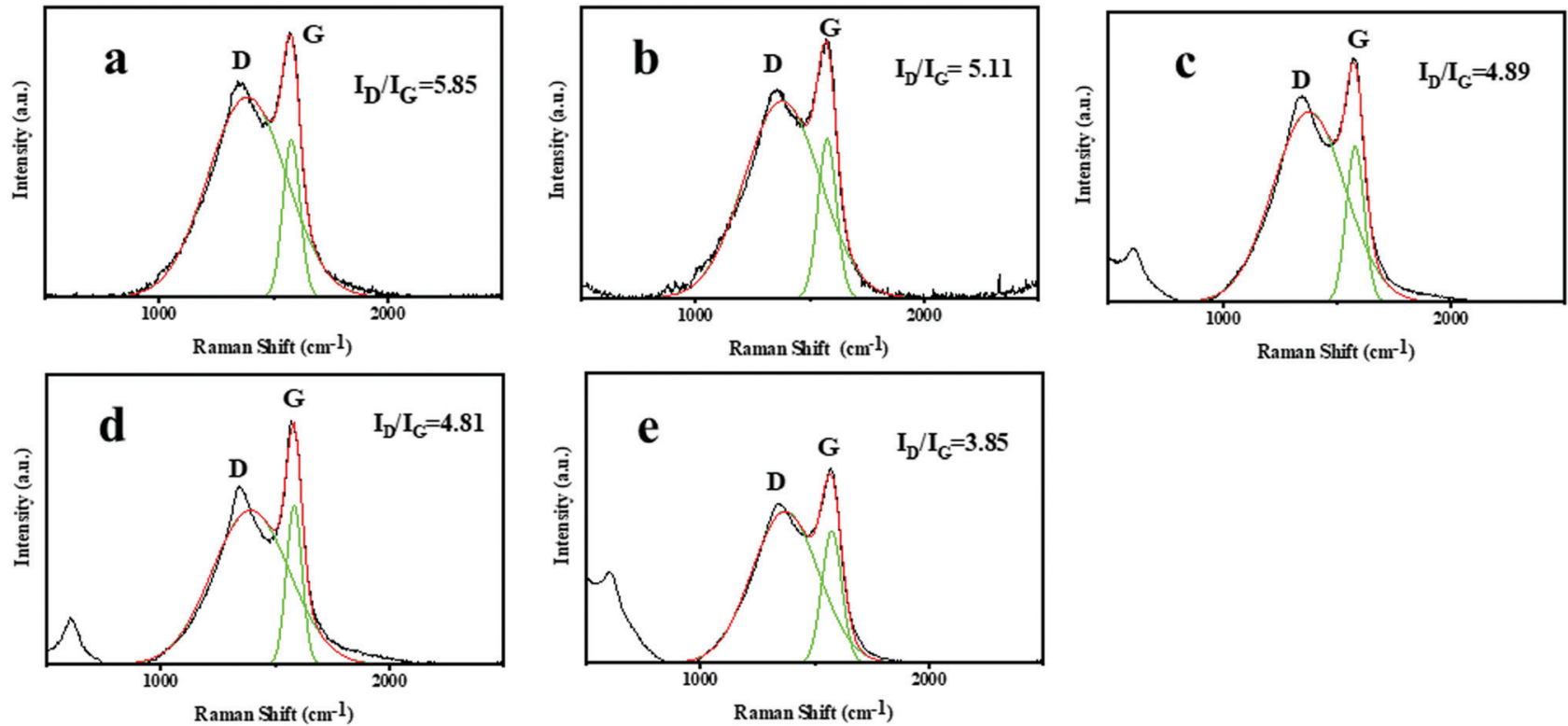

Fig. 13 Raman spectra of the friction surfaces of NR (a), NR/1TiO $2-C N T s$ (b), NR/2TiO $2-C N T s$ (c), NR/3TiO $2-C N T s(d)$, and NR/5TiO $2-C N T s$ (e).

\section{Conclusions}

The $\mathrm{TiO}_{2}-\mathrm{CNTs}$ hybrid was prepared by the sol-gel method in the current work. Different measurements demonstrate that $\mathrm{TiO}_{2}-\mathrm{CNTs}$ have a tubular structure, for which the inner tube is CNT and the outer particles are $\mathrm{TiO}_{2}$. When the $\mathrm{TiO}_{2}-\mathrm{CNTS}$ were used to fabricate the $\mathrm{NR} / \mathrm{TiO}_{2}-\mathrm{CNTs}$ composites, it was found that only $3.0 \mathrm{wt} \%$ of $\mathrm{TiO}_{2}-\mathrm{CNTs}$ endowed NR with significantly improved tensile strength and elastic modulus, which were 32.0 MPa and 4.1 MPa, respectively, which correspondingly increased by $66.7 \%$ and $41.4 \%$ compared with that of NR. More importantly, the stability of NR under extreme friction condition was greatly improved. The maximum temperatures at the friction surfaces of $\mathrm{NR} / 3 \mathrm{TiO}_{2}-\mathrm{CNTs}$ and NR/ $5 \mathrm{TiO}_{2}-\mathrm{CNTs}$ were greatly reduced by 29 and $36{ }^{\circ} \mathrm{C}$, respectively, compared with that for NR. The mechanisms for the mechanical enhancement of NR and the improved stability of the $\mathrm{NR} / \mathrm{TiO}_{2}-$ CNTs composites under extreme friction condition were deeply discussed. All these experimental results demonstrated that the hybridization of both $\mathrm{TiO}_{2}$ and CNTs may efficiently and simultaneously achieve the mechanical enhancement of natural rubber and its stability under extreme friction condition, and the $\mathrm{TiO}_{2}-\mathrm{CNTs}$ have a potential value in the tread material of aircraft tires.

\section{Conflicts of interest}

There are no conflicts to declare.

\section{Acknowledgements}

This work was supported by the National Natural Science Foundation of China (No. 51790504, 51673132, 51827803, and 51991351).

\section{References}

1 M. J. Matheson, T. P. Wampler and W. J. Simonsick, The effect of carbon-black filling on the pyrolysis behavior of natural and synthetic rubbers, J. Anal. Appl. Pyrolysis, 1994, 29(2), 129-136.

2 S. Straus and S. L. Madorsky, Thermal degradation of unvulcanized and vulcanized rubber in a vacuum, Ind. Eng. Chem., 1956, 48(7), 1212-1219.

3 D. D. Jiang, G. F. Levchik, S. V. Levchik, C. Dick, J. J. Liggat, C. E. Snape and C. A. Wilkie, Thermal degradation of crosslinked polyisoprene and polychloroprene, Polym. Degrad. Stab., 2000, 68(1), 75-82.

4 J. W. Hao, C. A. Wilkie and J. Q. Wang, An XPS investigation of thermal degradation and charring of cross-linked polyisoprene and polychloroprene, Polym. Degrad. Stab., 2001, 71(2), 305-315.

5 D. W. Brazier and G. H. Nickel, Thermoanalytical methods in vulcanizate analysis.1. differential scanning calorimetry and heat of sulfur vulcanization, Rubber Age, 1974, 106(9), 52-53.

6 J. Xigao and L. Huiming, Determination of the cross-link density of vulcanized polyisoprene by pyrolysis-gas chromatographymass spectrometry, J. Anal. Appl. Pyrolysis, 1981, 3(1), 49-57.

7 F. Z. Chen and J. L. Qian, Studies on the thermal degradation of cis-1,4-polyisoprene, Fuel, 2002, 81(16), 2071-2077.

8 R. S. L. Sally and A. Groves, MarianneBlazsó,TamásSzékely, Natural rubber pyrolysis: Study of temperature-and thickness-dependence indicates dimer formation mechanism, J. Anal. Appl. Pyrolysis, 1991, 19, 301-309.

9 H. Pakdel, D. M. Pantea and C. Roy, Production of dl-limonene by vacuum pyrolysis of used tires, J. Anal. Appl. Pyrolysis, 2001, 57(1), 91-107.

10 J. C. W. ChienJ and K. Y. Kiang, Polymer reactions-X thermal pyrolysis of poly(isoprene), Eur. Polym. J., 1979, 15(11), 1059-1065. 
11 S. Khanlari and M. Kokabi, Thermal Stability, Aging Properties, and Flame Resistance of NR-Based Nanocomposite, J. Appl. Polym. Sci., 2011, 119(2), 855-862.

12 G. Sui, W. Zhong, X. P. Yang, Y. Yu and S. Zhao, Preparation and properties of natural rubber composites reinforced with pretreated carbon nanotubes, Polym. Adv. Technol., 2008, 19(11), 1543-1549.

13 M. A. Lopezmanchado, J. Biagiotti, L. Valentini and J. M. Kenny, Dynamic mechanical and Raman spectroscopy studies on interaction between single-walled carbon nanotubes and natural rubber, J. Appl. Polym. Sci., 2004, 92(5), 3394-3400.

14 N. Hayeemasae, H. Ismail, S. Matchawet and A. Masa, Kinetic of thermal degradation and thermal stability of natural rubber filled with titanium dioxide nanoparticles, Polym. Compos., 2019, 40(8), 3149-3155.

15 J. Gong, R. Niu, N. Tian, X. C. Chen, X. Wen, J. Liu, Z. Y. Sun, E. Mijowska and T. Tang, Combination of fumed silica with carbon black for simultaneously improving the thermal stability, flame retardancy and mechanical properties of polyethylene, Polymer, 2014, 55(13), 2998-3007.

16 L. Bai, X. Wang, J. Tan, H. Li and J. Zheng, Study of distinctions in the synergistic effects between carbon nanotubes and different metal oxide nanoparticles on enhancing thermal oxidative stability of silicone rubber, J. Mater. Sci., 2016, 51(15), 7130-7144.
17 B. Gao, G. Z. Chen and G. L. Puma, Carbon nanotubes/ titanium dioxide $\left(\mathrm{CNTs} / \mathrm{TiO}_{2}\right)$ nanocomposites prepared by conventional and novel surfactant wrapping sol-gel methods exhibiting enhanced photocatalytic activity, Appl. Catal., B, 2009, 89(3-4), 503-509.

18 N. Lachman, X. Sui, T. Bendikov, H. Cohen and H. D. Wagner, Electronic and mechanical degradation of oxidized CNTs, Carbon, 2012, 50(5), 1734-1739.

19 Y. Wang, X. Qiu and J. Zheng, Study the mechanism that carbon nanotubes improve thermal stability of polymer composites: An ingenious design idea with coating silica on CNTs and valuable in engineering applications, Compos. Sci. Technol., 2018, 167, 529-538.

20 M. Koc, Y. Aueulan and T. Altan, On the characteristics of tubular materials for hydroforming-experimentation and analysis, Int. J. Mach. Tools Manufacture, 2001, 41(5), 761-772.

21 T. Zribi, A. Khalfallah and H. Belhadjsalah, Experimental characterization and inverse constitutive parameters identification of tubular materials for tube hydroforming process, Mater. Des., 2013, 49, 866-877.

22 T. Midgley and A. L. Henne, Natural and synthetic rubber I Products of the destructive distillation of natural rubber, J. Am. Chem. Soc., 1929, 51(1-4), 1215-1226.

23 F. Cataldo, Thermal depolymerization and pyrolysis of cis-1,4-polyisoprene: preparation of liquid polyisoprene and terpene resin, J. Anal. Appl. Pyrolysis, 1998, 44(2), 121-130. 